Submission to ASICON 2005

Corresponding Author: Faisal Mohd Yasin

Address: Faculty of Engineering

Multimedia University, Cyberjaya 63100 Selangor

E-mail: faisal.yasin@mmu.edu.my

Phone: +60383125423

Fax: +60383133029

Title of Paper: CMOS-Based Gas Sensor: SoC Approach 


\title{
CMOS-Based Gas Sensor: SoC Approach
}

\author{
F. Mohd-Yasin, K.F. Tye, C.Y. Lee, M.B.I. Reaz Member IEEE
}

\section{Summary}

The design of CMOS-based SAW gas sensor with a system on chip (SoC) approach is presented in this paper. The SAW sensor devices typically run at RF, requiring most design to have complex signal conditioning circuitry. Our approach attempts to simplify the design while operating at $354 \mathrm{MHz}$. An algorithm has been developed to get the optimized solution for the SAW sensor's design parameters. In the simulations the tungsten trioxide $\left(\mathrm{WO}_{3}\right)$ film is used as a sensing element to detect hydrogen sulfide $\left(\mathrm{H}_{2} \mathrm{~S}\right)$. The signal processing circuitry is designed using TSMC $0.35 \mathrm{u}$ technology. It could detect the input which is in the form of frequency ranging from $300 \mathrm{MHz}$ to $400 \mathrm{MHz}$. Simulation data show that this design has $30 \%$ reduced power and 10 time lesser die size, compare to two existing works.

The CMOS SAW gas sensor is designed using the Mentor Graphics design tools based on TSMC 0.35um technology. Figure 1 shows the layout of the entire system. Numerous simulations have been performed to get the optimized design. The results obtained based on different number of IDT finger pairs and overlap length are shown in Figure 2 and 3. Finally, the final output (in voltage) from the signal conditioning circuitry is presented in Figure 4. 


\section{Figures}

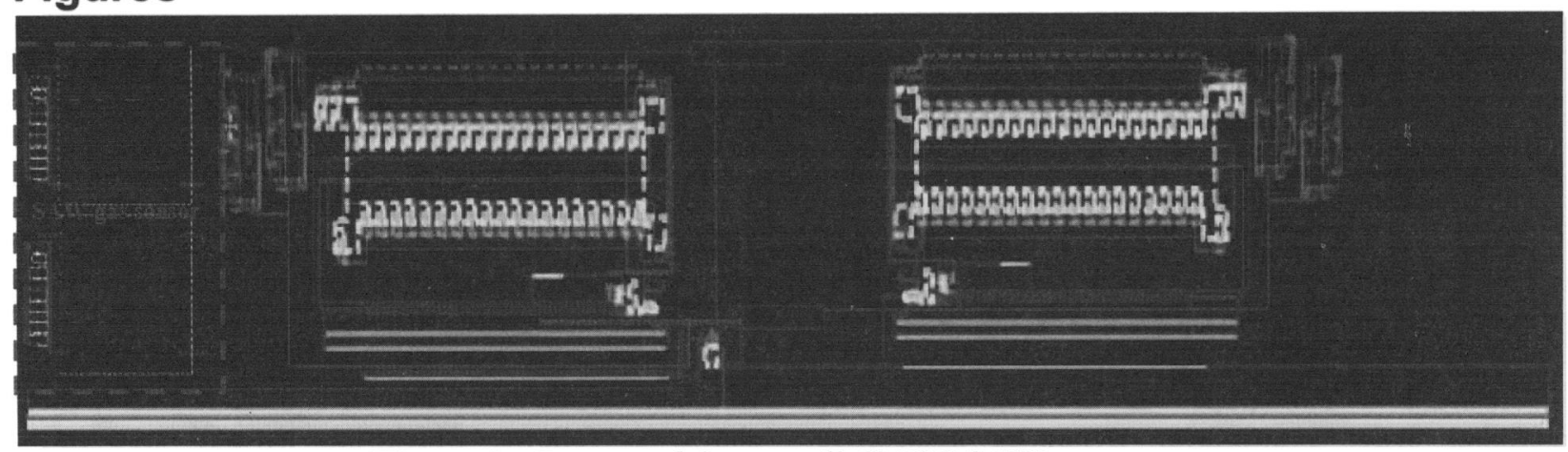

Figure 1 - Layout of the overall CMOS SAW gas sensor

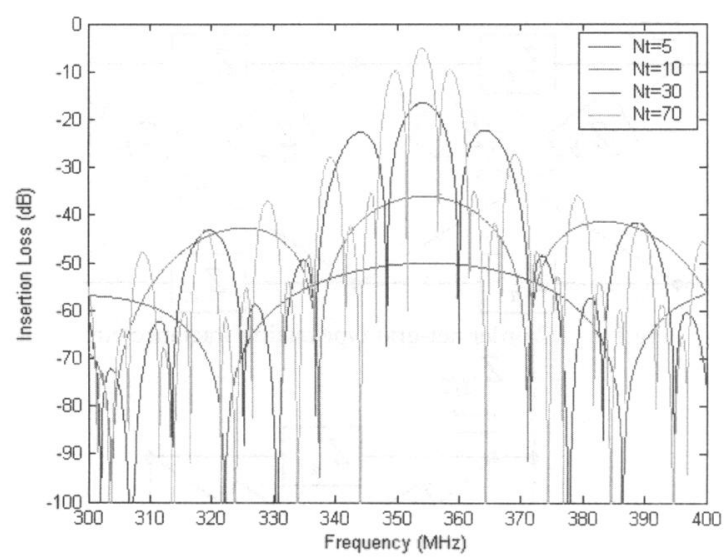

Figure 2 - Simulation of IDT with different fingers $(\mathrm{Nt})$

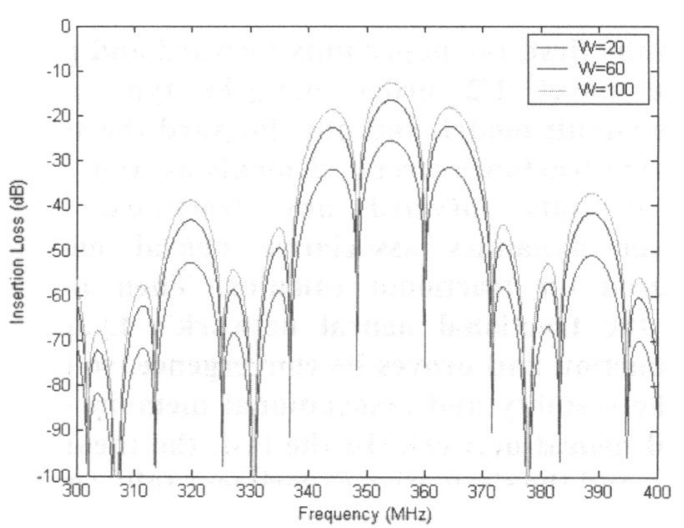

Figure 3 - Simulation of IDT with different overlap length (W)

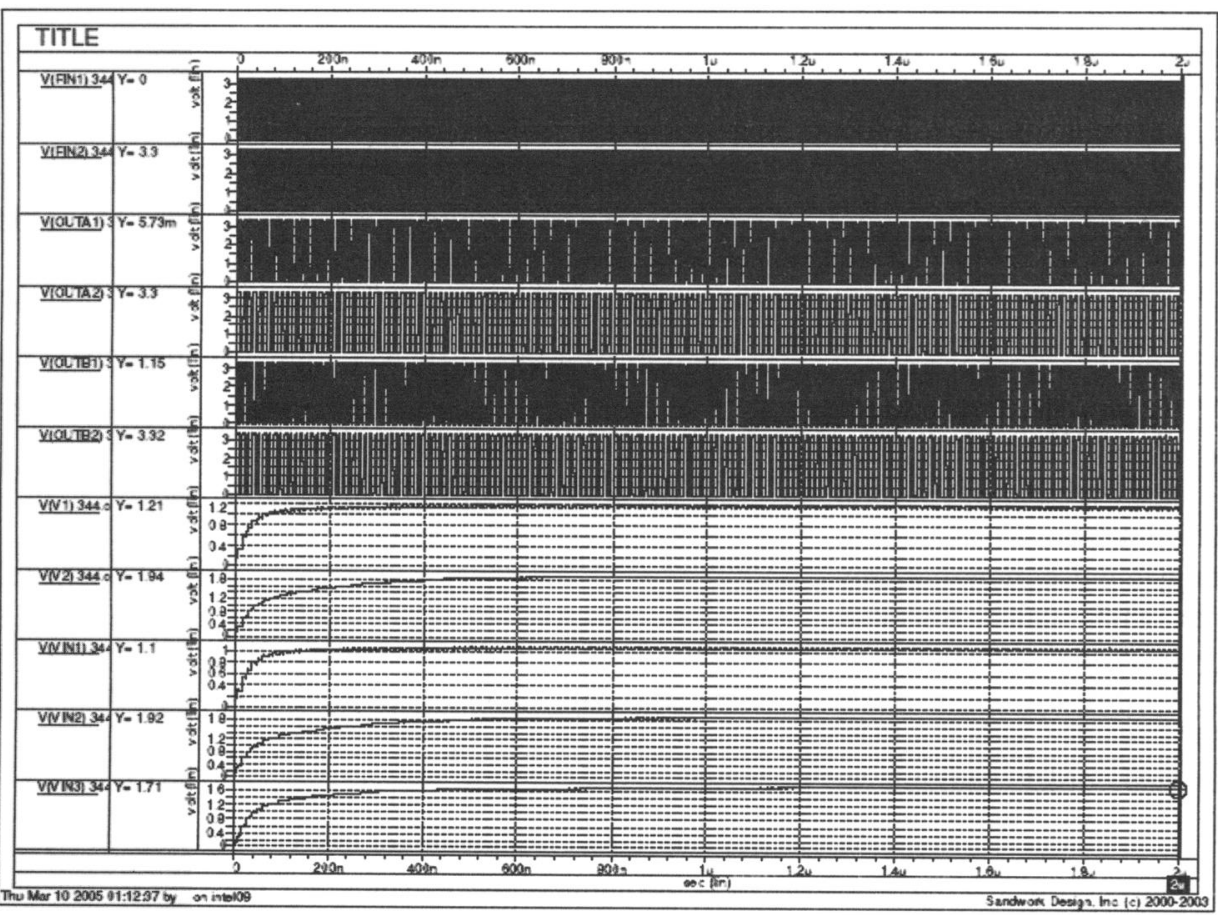

Figure 4 - Simulation result from signal conditioning circuitry. 